DOI 10.1007/s10958-022-05722-1

Journal of Mathematical Sciences, Vol. 260, No. 6, February 2022

\title{
SIRIUS MATHEMATICS CENTER AS A NEW CENTER OF MATHEMATICAL CONFERENCES
}

\author{
A. Laptev \\ Imperial Colledge London \\ Huxley Building, 180 Queen's Gate, London SW7 AZ, UK \\ Sirius Mathematics Center \\ P.O. Box 99, 2, Lenina St., Sochi 354340, Russia \\ Saint Petersburg State University \\ 28, Universitetsky pr., Saint Petersburg 198504, Russia \\ a.laptev@imperial.ac.uk
}

Professor Ari Laptev presents the recently founded Sirius Mathematics Center and the Conference of World-Class International Mathematical Centers held on August 9-13, 2020 in Sirius, Russia. Illustrations: 3 figures.

Sirius Mathematics Center http://siriusmath.ru located near the Olympic Park in the city of Sochi, Russia on the Black Sea coast was founded on November 2019 by the Talent and Success Educational Foundation. The mission of the Center is to organize and held scientific and educational events on contemporary topics in mathematics and applications.

Three main directions can be distinguished in the activities of the Sirius Mathematics Center.

1. Organization of international mathematical conferences for discussing new results, methods, and approaches in different fields of the mathematical sciences.

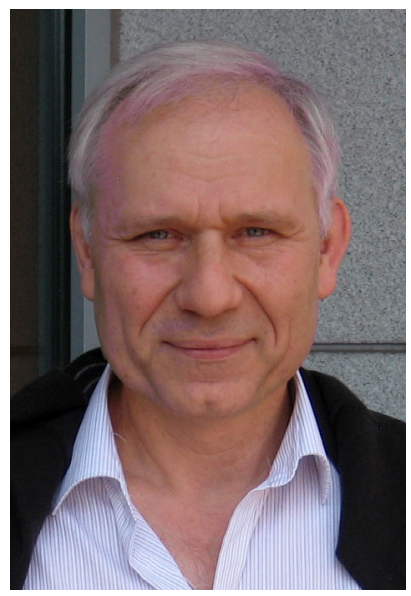

2. Organization of workshops for young researchers from Russia and other countries in order to prepare talented young mathematicians for scientific work in mathematics. Worldrecognized mathematicians from different countries are invited to give lectures.

3. Creation of conditions for research groups for their joint work on actual problems of mathematics and related disciplines, preparation of monographs and surveys.

Despite the difficulties caused by the pandemic, Sirius Mathematics Center held about 13 events in 2021, schools for young scientists and conferences on geometry and homological mirror

Translated from Problemy Matematicheskogo Analiza 113, 2022, pp. 3-6.

1072-3374/22/2606-0711 (C) 2022 Springer Science+Business Media, LLC 
symmetry, probabilistic method in analysis, mathematical problems of modern mathematical physics, computer algebra, spectral theory, toric topology and combinatorics and other areas of mathematics.

An important event in the mathematical life in Russia was the Conference of world-class international mathematical centers, held on the basis of Sirius Mathematics Center on August 9-13, 2021.

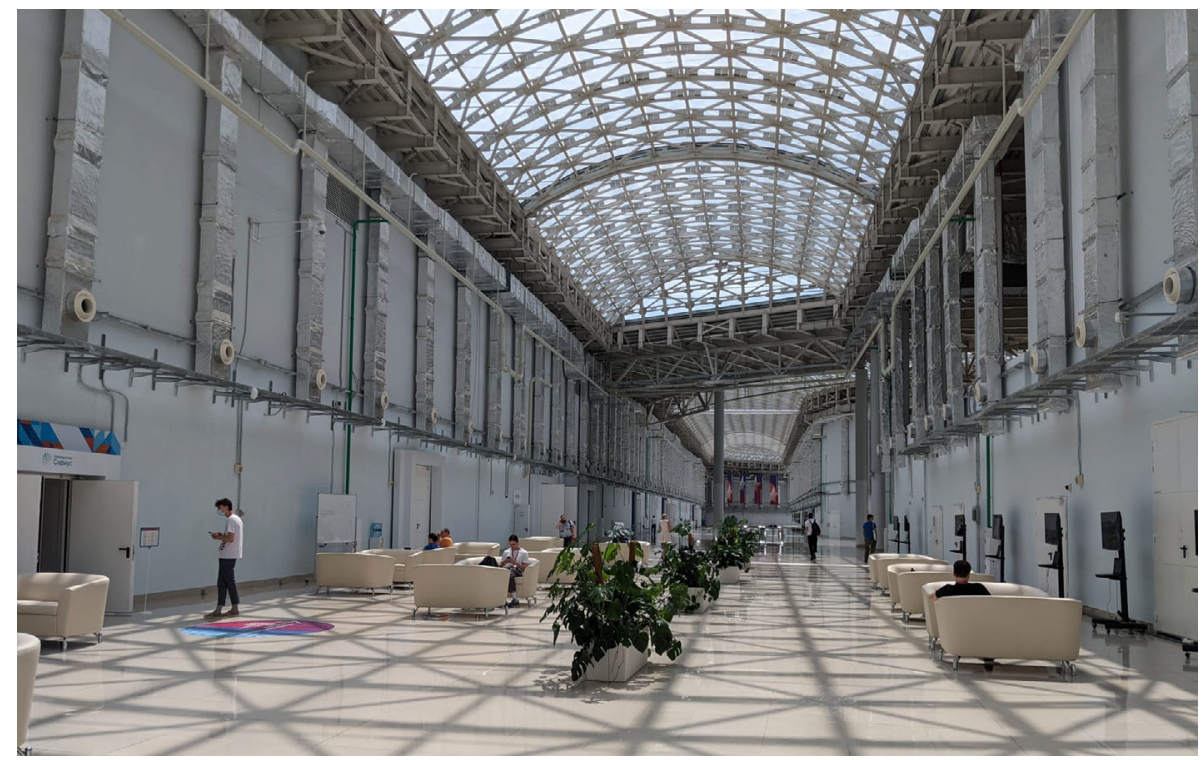

Interior of the Sirius Mathematics Center (http://siriusmathcenter.ru).

During the meeting with the President of the Russian Federation V. V. Putin, the rector of Moscow State University Professor V. A. Sadovnichy suggested to organize a Russian conference of international mathematical centers at the Sirius Educational Center. This initiative was supported, and it was decided to give this duty to the recently built Sirius Mathematics Center.

The appropriate funding for organizing the conference was equally distributed between the four centers: Moscow Center for Fundamental and Applied Mathematics, World-Class Mathematical Center MIAN, Euler International Mathematical Institute (Saint Petersburg), and Mathematical Center in Akademgorodok (Novosibirsk).

The aim of the conference was to contribute to the intensification of scientific research in mathematics in Russia and consolidate of the Russian mathematical community before the International Congress of Mathematicians in Saint Petersburg in 2022.

The conference became an important forum, where Russian scientists were able to discuss topical mathematical problems with their colleagues, the forum where young scientists had an opportunity to present their scientific achievements.

The conference was organized in cooperation with the conference of the Russian Association of Mathematics Teachers, which was organized at the Sirius Center just after the of the Conference of world-class international mathematical centers.

Plenary lectures were given by leading Russian mathematicians chosen by the Scientific Committee of the conference during the morning sessions for all participants. In the afternoon, there were parallel lectures on specific areas of mathematics. The section were organized by the 
International and Regional Mathematical Centers. Altogether there were 15 sections. Besides, all participants of the conference were invited to present posters at poster sessions.

The Talent and Success Foundation headed by E. V Shmeleva financially supported 9 prizes to young mathematicians in three categories: three prizes to students at the bachelor's and master's level, three prizes to $\mathrm{PhD}$ students and three prizes to young mathematicians being not older than 35 years old. A prize committee chaired by Professor A. Yu. Okunkov was created with responsibilities that included selection of 3 prize-winners in the category up to 35 years old that were awarded at the opening ceremony and selection of the winners in the first two categories during the conference that were awarded at the closing ceremony of the conference.

The conference attracted a large number of young and senior Russian mathematicians. Due to the pandemic there was a possibility to attend the conference on line. However, among more that 700 registered participants there were more than 320 participant who came to Sirius in person.

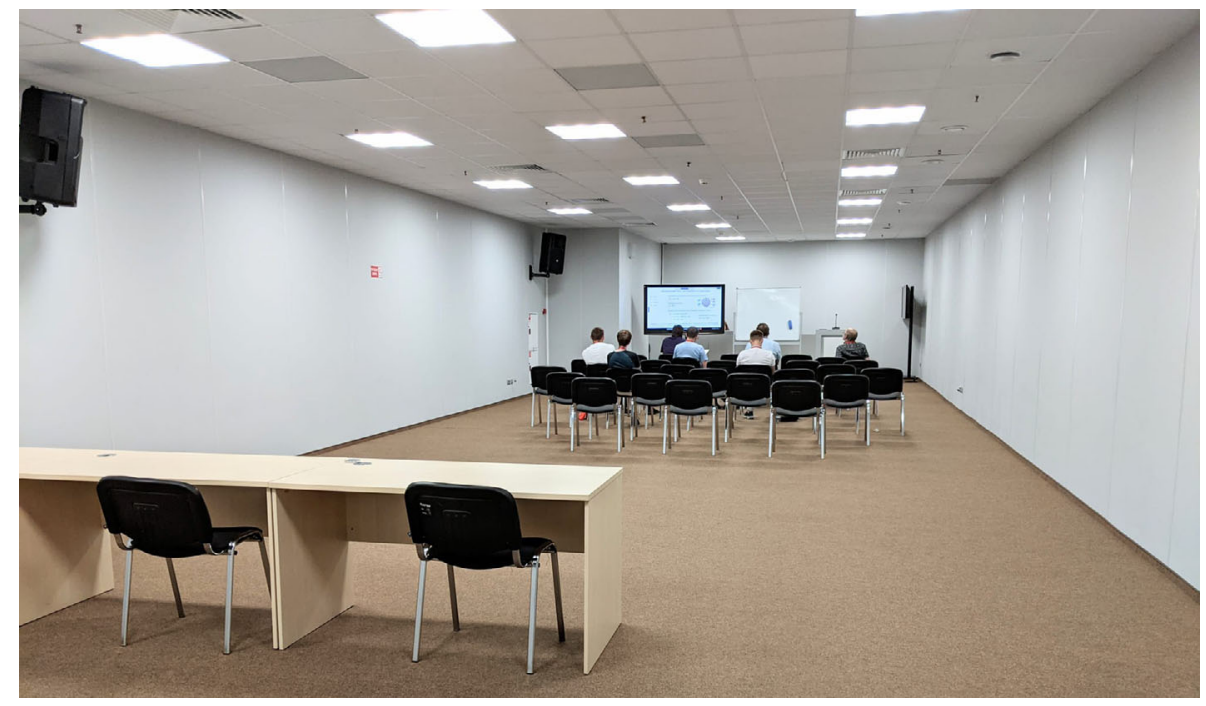

Hybrid (on-line and in person) lectures at the Conference of world-class international mathematical centers.

The Conference of world-class international mathematical centers in Sirius was definitely one of the major events in within the Russian mathematical community.

\section{Members of the Organizing Committee}

Co-chairs: V. A. Sadovnichy and A. A. Laptev; Deputies: D. V. Treschev and A. V. Shchuplev; N. Yu. Anisimov, M. M. Arslanov, V. A. Vasiliev, E. P. Vdovin, A. Yu. Vesnin, M. A. Vsemirnov, A. A. Zavarzin, A. N. Karapetyants, B. S. Kashin, S. A. Kashchenko, S. V. Kislyakov, A. G. Kuznetsov, N. Yu. Lukoyanov, D. K. Mamiy, Yu. V. Matiyasevich, A. V. Mikhailov E. A. Mshagskaya, D. O. Orlov, V. E. Podolsky, G. M. Polotovsky, S. K. Smirnov, V. N. Ushakov, A. K. Tsikh, I. V. Yaschenko.

\section{Members of the Program Committee}

Chairman: I. A. Taimanov; Deputy: K. M. Khanin; A. Yu. Alekseev, A. I. Aptekarev, A. P. Veselov, Yu. M. Kabanov, L. V. Katsarkov, S. K. Lando, N. S. Nadirashvili, A. A. Razborov, 
N. A. Rozhkovskaya, A. G. Sergeev, M. L. Sodin, I. L. Sofronov, T. A. Suslina, A. S. Holevo, N. V. Tsilevich, D. S. Chelkak.

\section{List of plenary speakers}

A. Buryak (Moscow, Russia), E. Hirsch (Saint Petersburg, Russia), S. Dyatlov (Boston, USA), A. Efimov (Moscow, Russia), V. Gorin (Wisconsin, USA), S. Zelik (Surrey, UK / Moscow, Russia), D. Krotov (Novosibirsk, Russia), A. Logunov (Saint Petersburg, Russia / Princeton, USA), F. Petrov (Saint Petersburg, Russia), V. Podolsky (Moscow, Russia), A. Skripchenko (Moscow, Russia), Yu. Trakhinin (Novosibirsk, Russia), D. Frolenkov (Moscow, Russia), S. Shaposhnikov (Moscow, Russia).

Ari Laptev

Chair of Scientific Council Sirius Mathematics Center

Submitted on Jaunary 10, 2022 